\title{
Evaluation of the Effects of Fluids Upon the Flexural and Parallel-plate Loading Behavior of Glass Fiber Reinforced-vinyl Ester Resin Matrix Composite Pipes
}

\author{
Ademi Nobeto da Silva ${ }^{a}$, Guilherme Sampaio Moria, Jose Roberto Moraes d'Almeida ${ }^{a, b *}$ \\ ${ }^{a}$ Mechanical Engineering Department, Universidade do Estado do Rio de Janeiro, \\ Rua São Francisco Xavier, 524, Maracanã, CEP 20550-090, Rio de Janeiro, RJ, Brazil \\ ${ }^{b}$ Materials Engineering Department, Pontifícia Universidade Católica do Rio de Janeiro, \\ Rua Marquês de São Vicente, 225, Gávea, CEP 22453-900, Rio de Janeiro, RJ, Brazil
}

Received: March 28, 2014; Revised: January 16, 2015

\begin{abstract}
Commercial glass fiber reinforced-vinyl ester resin composite pipes used in onshore and offshore utilities were exposed to the action of fluids that could normally come into contact with them during their service life, namely: salt water, biodiesel and a mixture of water and oil. The influence of these fluids upon the flexural properties and parallel-plate loading behavior of the composites was evaluated. The results of the mechanical tests point out that physical aging was the main phenomenon, and that it causes a reduction of stiffness of around $20-30 \%$ - at the parallel-plate test - and a decrease of toughness of up to $40 \%$ - at the flexural test. The results of the flexural tests were very dependent of the inhomogeneous microstructure of the commercial composite analyzed.
\end{abstract}

Keywords: glass fibers composites, environmental aging, mechanical properties, parallel-plate test

\section{Introduction}

The use of polymer composites at onshore and offshore facilities increased over the last years due to the several advantages of these materials in respect to more traditional materials, such as steel alloys. These advantages include a high specific strength - i.e., a high tensile strength to density ratio - what implies weight savings on a volume basis ${ }^{1}$.

For many industrial applications, in fact, weight saving can be a major factor to choose or not a material, and polymer matrix composite pipes have as one of their advantages low weight when compared to their steel counterparts. The ease and speed of assembling a light pipe is also fundamental in, for example, offshore facilities where any material or personnel to be transported to or allocated at the offshore plant has a substantially high cost. Polymers and polymer composites can, however, degrade when exposed to several common environments that they can be brought into contact during their service life. Ultraviolet radiation ${ }^{2-4}$ and humidity ${ }^{5}$ are the most common of the service environments that one could expect a resin matrix composite pipe to be exposed to. Their effects and prevention are well discussed in the literature ${ }^{6}$. However, several other environments can be expected to cause degradation to polymers and polymer composites; these include salt water ${ }^{7,8}$, and other common fluids, like diesel and petrol ${ }^{9-11}$. Although many works had already treated the problem of the interaction of several fluids with polymers and their composites ${ }^{5-12}$, generalization of the observed behavior is not, in many instances, a simple task. This is due to the fact that very particular interactions can occur between a specific composite and also the specific

*e-mail: dalmeida@puc-rio.br fluid under analysis; this aspect is especially true when the performance of a commercial material is being analyzed. When a commercial composite is being tested, and even when tight manufacturing parameters are used, local variations on the amount of cure, on the fiber distribution and fiber volume fraction, or on the volume fraction of voids can occur and can be a source of deviations of the expected composite behavior ${ }^{13}$.

Therefore, in this work, a study was undertaken to analyze the effect caused by fluids that can be ordinarily in contact with composite pipes - namely salt water, biodiesel and a mixture of water and oil - upon the flexural and parallel-plate loading behavior of a commercial glass fiber reinforced-vinyl ester resin matrix composite pipe.

\section{Material and Experimental Methods}

A commercial glass fiber-vinyl ester matrix reinforced composite pipe with proprietary specifications and manufactured by filament winding was used in this work. The as received $2000 \mathrm{~mm}$ long pipe had nominal external diameter of $115 \mathrm{~mm}$ and thickness of $7.3 \mathrm{~mm}$.

Flexural specimens $125 \mathrm{~mm}$ long and $25.5 \mathrm{~mm}$ large were machined along the longitudinal direction of the pipe. These specimens were machined $30 \mathrm{~mm}$ apart from each other, along the pipes' length, in order to encompass possible variations on the fiber volume fraction and spatial distribution along the pipes' length. This procedure has the objective to give average values for the properties being evaluated. The three point bending tests were performed following the ASTM D $790^{14}$ standard. The test span used 
was of $85 \mathrm{~mm}$, giving therefore a span to depth ratio of 11 , and the test speed used was of $5 \mathrm{~mm} / \mathrm{min}$.

The parallel-plate loading behavior was performed on ring specimens $25 \mathrm{~mm}$ wide following the recommendations of ASTM D $2412^{15}$ standard. The ring specimens were also machined from different positions along the pipes' length, in order to obtain the average behavior of the composite under test, even if variations on the fiber volume fraction and spatial distribution exist. Figure 1 shows a specimen positioned between the parallel plates at the test equipment. These tests were stopped when the diameter of the pipes presented a reduction of $10 \%$ in respect to its original diameter, and the test velocity used was of $2 \mathrm{~mm} / \mathrm{min}$.

Three different aging fluids were used, namely: a) salt water; b) biodiesel; and c) oily water. The specific characteristics of the biodiesel were: $\mathrm{pH} 5.9$; acidic index: $0.08 \mathrm{mg} / \mathrm{kg}$; specific gravity: $882 \mathrm{~kg} / \mathrm{m}^{3}$. The oily water has $87.7 \%$ of water and $\mathrm{pH}$ of 6.89 . The salt water was prepared following the recommendations of ASTM standard D $1141^{16}$. The test specimens were immersed into these fluids at ambient temperature, $23 \pm 2{ }^{\circ} \mathrm{C}$, during 6 months. Six specimens were tested per composite condition and test performed.

The microstructure of the composite was analyzed by optical microscopy. Samples were prepared following the usual mounting, grinding and polishing procedures. After being mounted on an epoxy base, the samples were grinded from sandpaper \# 220 to 1200 , and the polishing procedure used diamond paste from $6 \mu \mathrm{m}$ to $1 \mu \mathrm{m}$. Each grinding/polishing step lasted for about 3 minutes.

\section{Experimental Results and Discussion}

Figure 2 shows the common aspects of the composite's microstructure. One can see that a heterogeneous fiber distribution exists along the thickness of the composite's wall. Resin rich areas and voids are observed, and these areas are sources of weakness for this composite. The voids can act as stress raisers and serve as points for fluid accumulation. Resin rich areas are regions with low strength inside de composite serving as crack initiation points.

Figure 3 shows the compressive loads necessary to reduce the diameter of the parallel-plate loading specimens

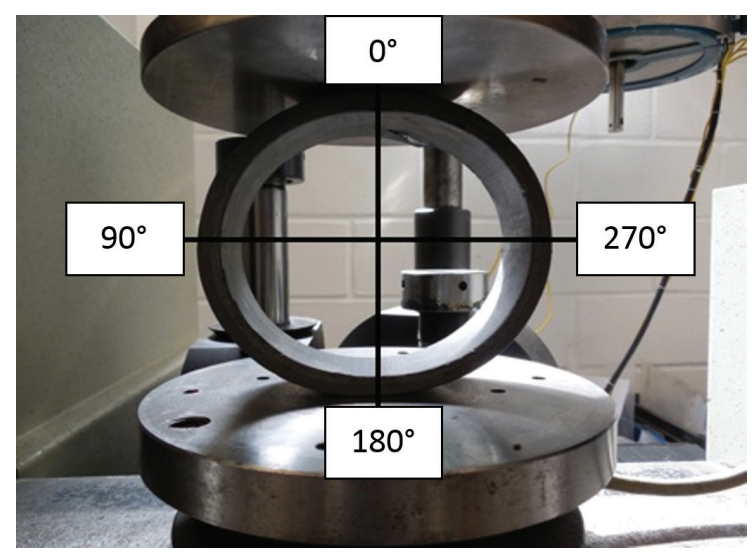

Figure 1. Parallel-plate test specimen positioned at the test equipment. by $10 \%$ before and after aging. One can see that all aging media affected the behavior of the composite, and a load bearing capacity reduction varying between $20-30 \%$ was noted. Using the $t$-Student test with a significance level of 0.05 the average values of the aged composites are not significantly different among each other, but they are significantly different in respect to the as-received composite.

Although the load bearing capacity of the aged composites in respect to the as received one was reduced, the macroscopic inspection by naked eye did not reveal the presence of cracks or delamination at the tensile side of all specimens, Figure 4a, regardless the composites being or not aged. This simple visual inspection is the standard practice, as recommended by ASTM D 2412 standard $^{15}$, to determine if a material fails or not in respect to the parallelplate loading test. At the compressive inner side, there were some whitening effects accompanying the fiber winding angle, Figure $4 \mathrm{~b}$. Whitened zones are associated to the development of debonding at the fiber-matrix interface ${ }^{17}$. At the compressive side of the test specimen, the presence of these marks could indicate that fiber buckling can be a failure mode of relevance. However, from the standard point of view all specimens were approved.

The results, however, point to a decrease of the specimens' stiffness. This same behavior was also observed for another glass fiber reinforced pipe after its exposure to tap water ${ }^{18}$, and can be attributed to the diffusion of the fluids to the interior of the matrix resin, and to the accompanying plasticization effect ${ }^{5}$. The diffusion of a liquid into a polymer usually produces, at least at the first stages of the diffusion process, physical aging of the polymer, with the fluid diffusing into the free volume of the macromolecular structure. The uniform decrease of the load capacity observed at Figure 3, seems to indicate that, for the aging time of this work, the effect of the fluids was, indeed, very similar, and one could expect that only physical aging is occurring.

The stiffness reduction of the parallel plate test can be evaluated using the following expression ${ }^{19}$ :

$$
\Delta \mathrm{L}=0.1488 \frac{\operatorname{Pr}^{3}}{\mathrm{EI}}
$$

where $\Delta \mathrm{L}$ is diameter reduction due to $P, P$ is the load, $r$ is the ring's radius, and $E$ is the flexural modulus. The moment of inertia, $I$, for the ring configuration is given by:

$$
I=\frac{b t^{3}}{12}
$$

where $b$ and $t$ are, respectively, the width and the thickness of the ring specimen. From Equation (1) it is clear that the value of $E$ decreased for the aged specimens, since the load $P$ decreased, as shown in Figure 3, and the other variables at Equation (1) are geometrical constant parameters ( $I$ and $r$ ), and $\Delta \mathrm{L}$ was an experimental constant parameter - all the rings were loaded to produce a $10 \%$ reduction of their original diameter. The calculated values of $E$ for the 


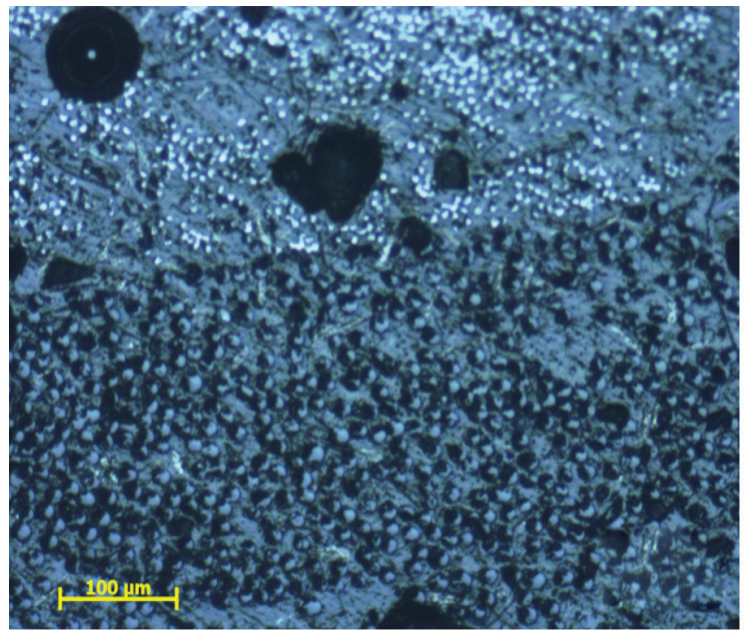

(a)

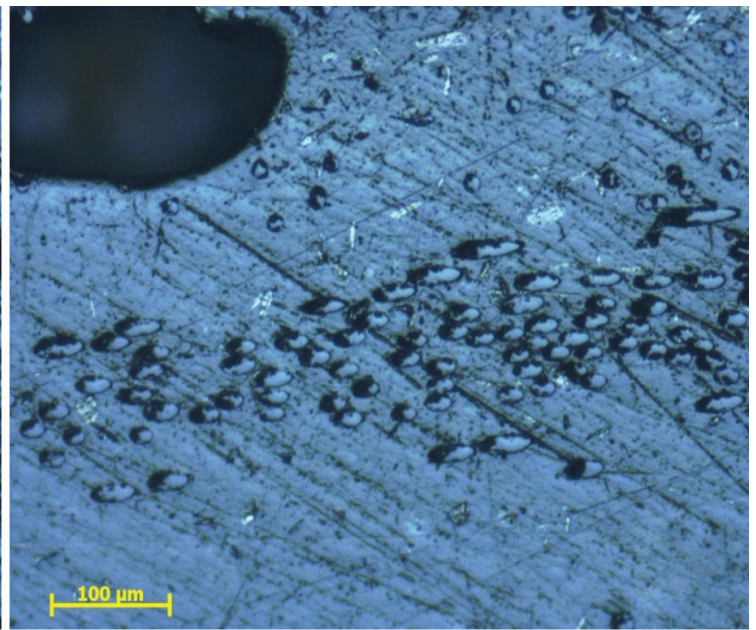

(b)

Figure 2. Uneven distribution of fibers along the composite pipe wall. a) Fiber rich region, and b) Resin rich areas and large voids can be observed.

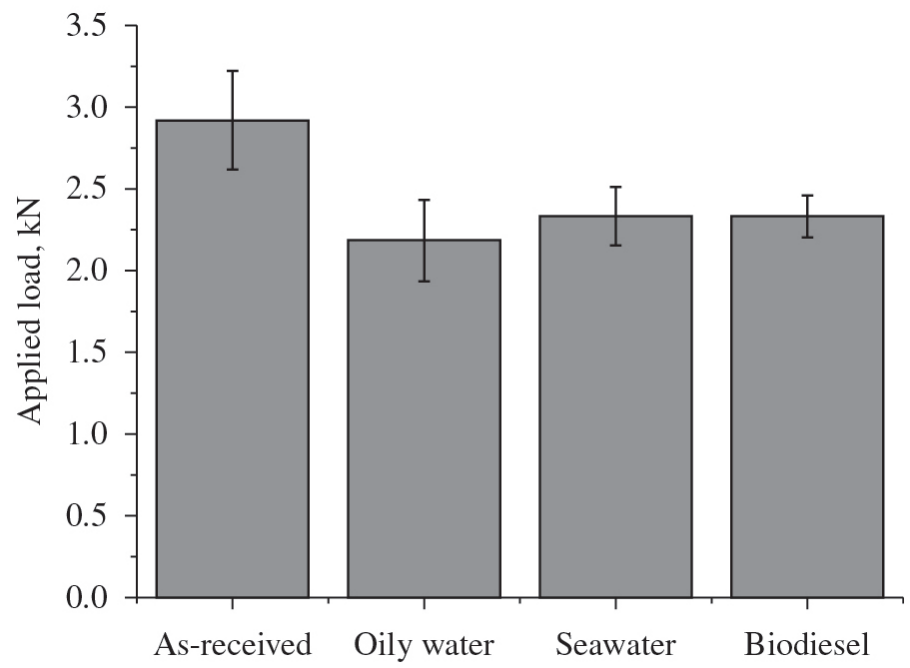

Figure 3. Load necessary to reduce the specimen's diameter by $10 \%$ of its original value.

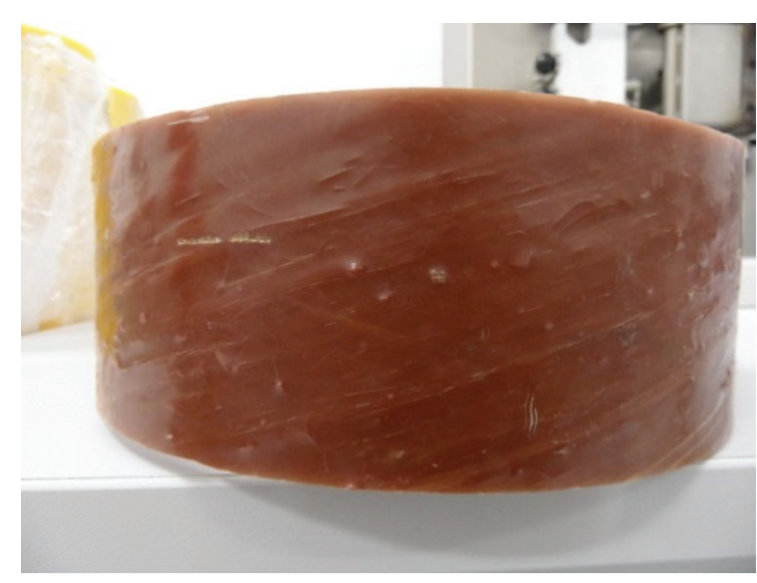

(a)

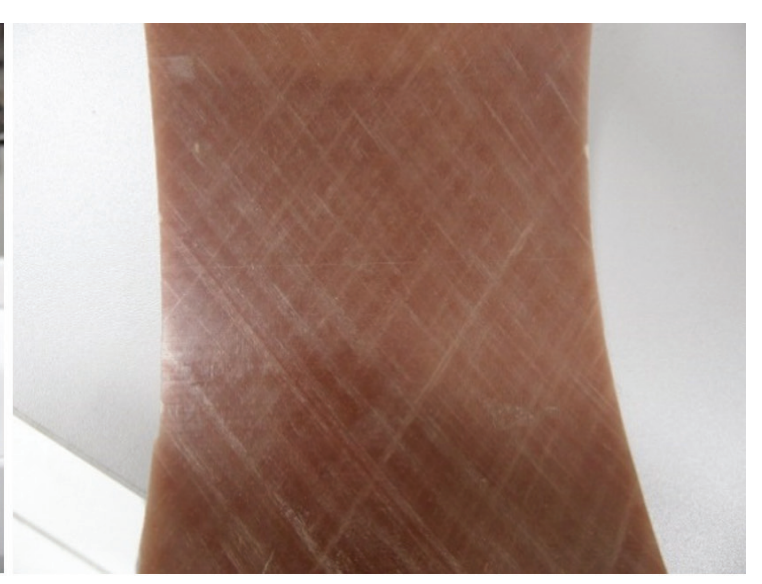

(b)

Figure 4. a) Macroscopic view of the tensile side $\left(90^{\circ}\right.$ position, see Figure 1$)$ of the tested specimens; and b) the inner surface, showing some whitening following the fiber winding directions. 
as-received and for the aged specimens were, respectively, 8.9 $\mathrm{GPa}$ and $6.9 \mathrm{GPa}$.

The results of the three-point bending flexure test, Figure 5, were not so straightforward. One can observe that the average flexural strength of the aged composites showed higher values than the average flexural strength of the as-received composite. The statistical analysis using the $t$-Student test with a significance level of 0.05 , however, showed that the values of the as-received and the composite immersed in oily water are not significantly different. The values for both salt water and biodiesel aged composites are statistically equal between each other, and are statistically different from the value of the as-received composite.

These results do reveal, however, the combined effects caused by plasticization, the very inhomogeneous microstructure observed for this composite, and also the stress state imposed by the flexure test. Plasticization enhances the toughness of the polymer matrix, and therefore can delay the propagation of a crack, favoring the attainment of a higher stress before the collapse of the composite. At the first stages of fluid absorption this could, therefore, increase the load bearing capacity of the material. For example, the interlaminar shear stress of carbon and glass fiber composites increased for the first stages of water absorption $^{20}$, and the fracture toughness parameter, $\mathrm{G}_{\mathrm{Ic}}$, also increased due to moisture for glass fiber composites with several different polymeric matrices, namely: orthopolyester, vinylester and epoxy ${ }^{21}$.

However, inhomogeneity of fiber distribution is, maybe, the leading factor behind the results presented at Figure 5. If a resin rich area, such as the one showed at Figure 2, is close to the outer layers of the composite, failure will be greatly favored when a three point bending test is performed, since the maximum stress is attained only at the outer layer, and occurs just at the single point under the central support. Therefore, any local variation of the fiber volume fraction or the presence of a high void content or resin rich areas can have a significant effect on the result obtained. It is important to highlight here that the tubes from where the specimens were machined are $2 \mathrm{~m}$ long, and after the microstructural analysis performed, large variation of the fiber distribution is likely to be found along the tube's length. This spatial variation of fiber and resin on a real commercial product

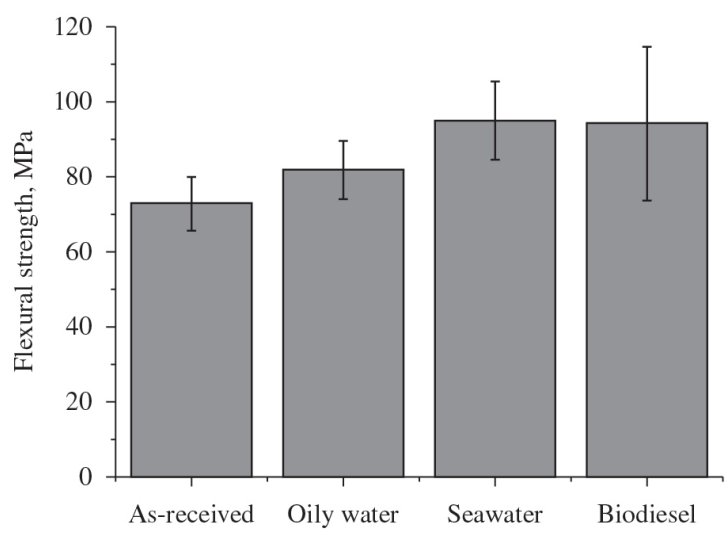

Figure 5. Variation of the flexural strength of the aged composites in respect to the as-received material. was, indeed, observed for other composites, even those that have a much more homogeneous microstructure ${ }^{4}$.

Figure 6 shows a tested specimen, where one can see that the failure begins at the surface of the composite, at the outermost layer at the tensile side of the test specimen, as it should be. One can also observe (Figure 6b) delamination across the specimen's thickness. Delamination was predominant at the tensile side of the specimen, decreasing as the neutral axis was approached.

Table 1 shows the variation of the flexural mechanical behavior of the composites before and after aging in terms of the flexural modulus, E, and also the initiation energy, $U_{i}$, defined as the area under the stress-strain curve until the maximum stress ${ }^{22}$. The increase of the flexural modulus for the aged specimens in relation to the value of the as-received composite corroborates the hypothesis that the large variation of the fiber volume fraction and of the fiber spatial distribution is the most influential parameter governing the mechanical behavior of this composite. However, is worth saying that moduli increase after aging is also reported in the literature ${ }^{12,23}$. Mouzakis and coworkers ${ }^{12}$ attributed the relative stiffening effect observed to a post-curing effect of the polyester matrix due to the effect of aging at a humid environment of the polyester/glass fiber reinforced composite they analyzed.

In respect to the energy absorbed one can see that the energy needed to begin the macroscopic crack propagation $\left(\mathrm{U}_{\mathrm{i}}\right)$ of the aged specimens decreased in respect to that of the as-received composite, indicating that aging is affecting the structural integrity of the composite and decreasing its toughness. There is not, however, a statistical difference between the results of the aged samples - using the $t$-Student test with a significance level of 0.05 . This result confirms the hypothesis that, under the aging conditions used in this work, the effect of the aging media was similar, and that physical aging is expected to be playing the major role.

From the data at Table 1, one can also observe that the values of $U_{i}$ for the aged specimens presented a very high standard deviation when compared to the standard deviation of the as-received composite. Crack initiation in composites is a complex issue since multiple different events can take place, such as fiber debonding, delamination or crack initiation at resin rich areas or at voids. Considering the very inhomogeneous microstructure of this commercial composite, the large standard deviations obtained do reflect the contribution of these several crack initiation events and the complexity of the heterogeneous microstructure. The decrease of the initiation energy indicates, however, that the mechanical performance of the composite is being affected by all aging media, and that the measured increase of the modulus and of the flexural strength are only an effect of

Table 1. Flexural modulus (E), and the energy consumed to initiate the macroscopic failure $\left(\mathrm{U}_{\mathrm{i}}\right)$.

\begin{tabular}{ccc}
\hline & $\mathbf{E}, \mathbf{G P a}$ & $\mathbf{U}_{\mathbf{i}}, \mathbf{1 0}^{\mathbf{6} . \mathbf{J}} / \mathbf{m}^{\mathbf{3}}$ \\
\hline As-received & $2.89 \pm 0.47$ & $3.58 \pm 0.42$ \\
Oily water & $4.58 \pm 0.51$ & $1.82 \pm 1.30$ \\
Seawater & $5.13 \pm 0.62$ & $1.43 \pm 1.11$ \\
Biodiesel & $5.41 \pm 1.61$ & $1.69 \pm 1.15$ \\
\hline
\end{tabular}




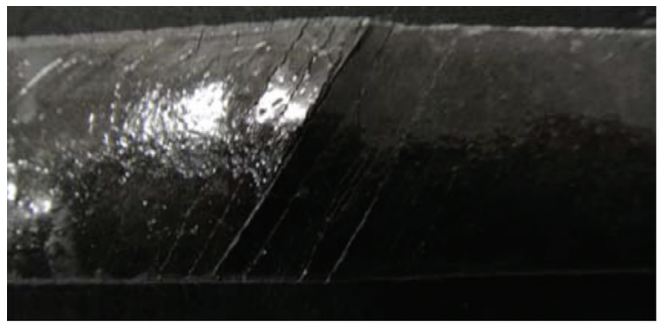

(a)

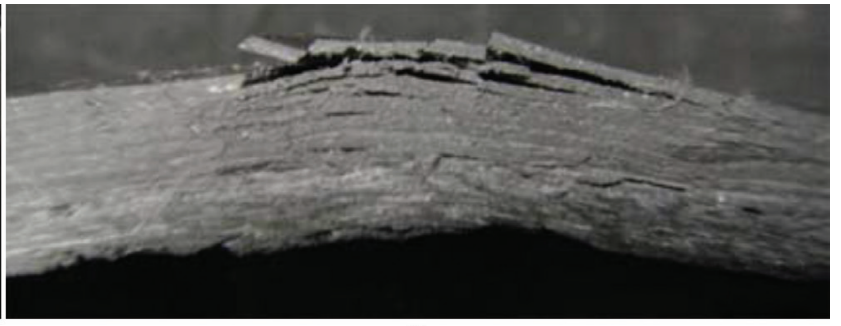

(b)

Figure 6. Macroscopic aspect of the failure of the three-point bending specimens. The crack started from the tensile stressed surface. a) Bottom view; b) Side view.

both the uneven microstructural characteristics and the particular stress state imposed by the three-point bending test, where the tensile stress varies along the specimens' thickness and the maximum bending moment is attained only at a single cross section.

\section{Conclusions}

Aging of a commercial glass fiber reinforced-vinyl ester resin composite pipe used in onshore and offshore utilities in salt water, biodiesel and oily water showed:

- Stiffness reduction of the aged composites in relationship to the as-received one under the stress state imposed by the parallel-plate loading test.

- The statistically equal values of the load necessary to compress the aged composites between each other indicate that under the aging time used in this work, physical aging was the main phenomenon causing the reduction of stiffness.

- The same behavior was observed in respect to the decrease of the energy necessary to initiate

\section{References}

1. Gibson AG. The cost effective use of fibre reinforced composites offshore. Newcastle Upon Tyne: University of Newcastle Upon Tyne; 2003. Research report 039.

2. Kotnarowska D. Influence of ultraviolet radiation and aggressive media on epoxy coating degradation. Progress in Organic Coatings. 1999; 37(3-4):149-159. http://dx.doi. org/10.1016/S0300-9440(99)00070-3.

3. Signor AW, Van Landingham MR and Chin JW. Effects of ultraviolet radiation exposure on vinyl ester resins: characterization of chemical, physical and mechanical damage. Polymer Degradation \& Stability. 2003; 79(2):359-368. http:// dx.doi.org/10.1016/S0141-3910(02)00300-2.

4. Chacón YG, Paciornik S and d'Almeida JRM. Microstructural evaluation and flexural mechanical behavior of pultruded glass fiber composites. Materials Science and Engineering A. 2010; 528(1):172-179. http://dx.doi.org/10.1016/j.msea.2010.09.010.

5. Ellyin F. Durability of glass-fiber reinforced polymer composites in aqueous and high temperature environments. Polymers and Polymer Composites. 2004; 12:277-288.

6. Mercier J, Bunsell A, Castaing P and Renard J. Characterization and modelling of aging of composites. Composites. Part A, Applied Science and Manufacturing. 2008; 39(2):428-438. http://dx.doi.org/10.1016/j.compositesa.2007.08.015. macroscopic crack propagation at the flexural test. The results of the aged samples are not statistically different between each other, indicating a similar effect of the fluids upon the composite.

- The results of the flexural mechanical properties, i.e. the strength and modulus of the composites, were influenced by the inhomogeneous microstructure of the commercial composite analyzed and by the particular stress state imposed by a three pointbending test. Plasticization was identified as the phenomenon governing the variation of the flexural properties.

- The macroscopic failure of the composites submitted to the flexural test was initiated by tensile cracks and was followed by delamination across the thickness of the composites.

\section{Acknowledgements}

The authors greatly acknowledge the financial support from the Brazilian Agency CNPq.

7. Gellert EP and Turley DM. Seawater immersion ageing of glassfibre reinforced polymer laminates for marine applications. Composites. Part A, Applied Science and Manufacturing. 1999; 30(11):1259-1265. http://dx.doi.org/10.1016/S1359835X(99)00037-8.

8. Kootsookos A and Mouritz AP. Seawater durability of glass- and carbon-polymer composites. Composites Science and Technology. 2004; 64(10-11):1503-1511. http://dx.doi. org/10.1016/j.compscitech.2003.10.019.

9. D'Almeida JRM. Environmental effects on the interlaminar shear strength of aramid-epoxy composites. Journal of Materials Science Letters. 1989; 8(2):194. http://dx.doi. org/10.1007/BF00730722.

10. Sala G. Composite degradation due to fluid absorption. Composites. Part B, Engineering. 2000; 31(5):357-373. http:// dx.doi.org/10.1016/S1359-8368(00)00025-1.

11. Torres AHU, d'Almeida JRM and Habas J-P. Aging of HDPE pipes exposed to diesel lubricant. Polymer-Plastics Technology and Engineering. 2011; 50(15):1594-1599. http://dx.doi.org/1 0.1080/03602559.2011.578297.

12. Mouzakis DE, Zoga H and Galiotis C. Accelerated environmental ageing study of polyester/glass fiber reinforced composites (GFRPCs). Composites Part B: Engineering. 2008; 39(3):467475. http://dx.doi.org/10.1016/j.compositesb.2006.10.004.

13. Cohen D, Mantell SC and Zhao L. The effect of fiber volume fraction on filament wound composite pressure vessel strength. 
Composites Part B: Engineering. 2001; 32(5):413-429. http:// dx.doi.org/10.1016/S1359-8368(01)00009-9.

14. American Society for Testing and Materials - ASTM. ASTM D 790: standard test methods for flexural properties of unreinforced and reinforced plastics and electrical insulating materials. West Conshohocken: ASTM International; 2010.

15. American Society for Testing and Materials - ASTM. ASTM 2412: standard test method for determination of external loading characteristics of plastic pipe by parallel-plate loading. West Conshohocken: ASTM International; 2011.

16. American Society for Testing and Materials-ASTM. ASTMD 1141: standard practice for the preparation of substitute ocean water. West Conshohocken: ASTM International; 2013.

17. Parvizi A and Bailey JE. On multiple transverse cracking in glass fibre epoxy cross-ply laminates. Journal of Materials Science. 1978; 13(10):2131-2136. http://dx.doi.org/10.1007/ BF00541666.

18. d'Almeida JRM, Almeida RC and de Lima WR. Effect of water absorption of the mechanical behavior of fiberglass pipes used for offshore service waters. Composite Structures. 2008; 83(2):221-225. http://dx.doi.org/10.1016/j. compstruct.2007.04.020.

19. Young WC and Budynas RG. Roark's formulas for stress and strain. 7th ed. New York: McGraw-Hill; 2002.

20. Ray BC. Temperature effect during humid ageing on interfaces of glass and carbon fibers reinforced epoxy composites. Journal of Colloid and Interface Science. 2006; 298(1):111-117. http:// dx.doi.org/10.1016/j.jcis.2005.12.023. PMid:16386268

21. Li M. Temperature and moisture effects on composite materials for wind turbine blades. [Dissertation]. Bozeman: Montana State University; 2000.

22. Hertzberg RW. Deformation and frature mechanics of engineering materials. 3rd ed. New York: John Wiley; 1989.

23. Kootsookos A, Mouritz AP and St John NA. Comparison of the seawater durability of carbon- and glass-polymer composites. In: Proceedings of the 13th International Conference on Composite Materials; 2001; Beijing, China. Paper ID-1200. 